\title{
A Meal Detection Algorithm for the Artificial Pancreas: A Randomized Controlled Clinical Trial in Adolescents with Type 1 Diabetes
}

\section{Supplementary Data}

\section{Participants}

From January 2018 to October 2019, adolescents with type 1 diabetes were recruited from the Montreal Children's Hospital. A block balanced randomization with a block size of six was used to determine the order of the interventions. Randomization was disclosed after the admission visit. Participants and investigators were not blinded to the allocation. Participants were blinded to insulin infusions and sensor glucose data during interventions. 13 adolescents were admitted to the study. One dropped out after the admission visit due to lack of time to participate. Another dropped out after the AP and AP+MDA interventions and before the CSII intervention and was excluded from analysis because they received a hypoglycemia overtreatment before lunch during the AP intervention, which made their post-lunch data unrepresentative. Eleven participants were included in the analysis.

\section{Meal Composition}

Meals were self-selected and standardized between interventions of each participant but were different between participants. Breakfast (40-50g of carbohydrates) was served at the start of the intervention, and lunch (55-65g of carbohydrates) was served 4 hours after the start of the intervention. For lunch, participants chose one main meal component and 1-4 sides (which added up to 55-65g of carbohydrates). The three main meal component choices were: (i) fettuccini alfredo (Michelina's) containing 35g CHO, 8g protein, 8g fat, (ii) chicken pesto rotini and vegetables (Healthy Choice) containing 33g CHO, 20g protein, $7 \mathrm{~g}$ fat, and (iii) general tao spicy chicken and rice (Healthy Choice) containing $44 \mathrm{~g}$ CHO, $16 \mathrm{~g}$ protein, $3.5 \mathrm{~g}$ fat. Side options included yogurt, vegetables, fruits, crackers, cookies, milk, and/or juice.

\section{Hypoglycemia and Hyperglycemia}

Hypoglycemia was treated with $16 \mathrm{~g}$ of oral carbohydrates if sensor glucose was below 3.3 $\mathrm{mmol} / \mathrm{L}$ and associated with symptoms, or below $3.0 \mathrm{mmol} / \mathrm{L}$ irrespective of symptoms. If glucose levels were not above $3.9 \mathrm{mmol} / \mathrm{L} 15$ minutes after treatment, another $16 \mathrm{~g}$ of oral carbohydrates were given. A hyperglycemia event was defined when glucose reached $17 \mathrm{mmol} / \mathrm{L}$ or was above $15 \mathrm{mmol} / \mathrm{L}$ for 90 minutes. Hyperglycemia events were corrected with an insulin bolus. During CSII, corrections were calculated using the participant' pump bolus calculator (current glucose target / sensitivity). During AP and AP+MDA, the corrections were calculated using the participant' pump bolus calculator (current glucose - target / sensitivity) minus the insulin-onboard from the closed-loop basal delivery. Blood ketones were checked for safety if blood glucose was above $20 \mathrm{mmol} / \mathrm{L}$.

There were 5 hyperglycemia events requiring correction boluses in the CSII arm, 4 events in the AP arm, and 1 event in the AP+MDA arm (Table 1). In the CSII arm, hyperglycemia events occurred at $1.5 \mathrm{~h}, 1.66 \mathrm{~h}, 2.0 \mathrm{~h}, 2.33 \mathrm{~h}$, and $3.0 \mathrm{~h}$ post meal. In the AP arm, hyperglycemia events 


\section{A Meal Detection Algorithm for the Artificial Pancreas: A Randomized Controlled Clinical Trial in Adolescents with Type 1 Diabetes}

occurred at $1.0 \mathrm{~h}, 1.33 \mathrm{~h}, 2.0 \mathrm{~h}$, and $3.0 \mathrm{~h}$ post meal. In the AP+MDA arm, the hyperglycemia event occurred at $1.5 \mathrm{~h}$ post meal. One participant had a hyper event in all three arms, two participants had a hyper in the CSII and AP arms, two participants had a hyperglycemic event in the CSII arm, and one participant had one hyperglycemic event in the AP alone arm.

\section{Statistical Analysis}

The primary endpoint was the incremental area under the curve (iAUC) of the postprandial (0h-4h) glucose excursions after lunch. The study was powered to detect a minimum difference between the interventions of $2.6 \mathrm{~h} . \mathrm{mmol} / \mathrm{L}$ in the primary endpoint. The primary comparison was designated to be between the AP and CSII interventions, and the comparisons between the $\mathrm{AP}+\mathrm{MDA}$ and the AP and CSII interventions were designated as secondary comparisons, and therefore, we did a power analysis using the sample size formula for the paired t-test with $5 \%$ significance level. We calculated that 12 participants would provide $80 \%$ power to detect differences between the interventions.

We used the two-sample t-test for outcomes with normally distributed data, and the Wilcoxon rank-sum test for outcomes with non-normally distributed data. For normally distributed outcomes, we reported means and standard deviations, and for non-normally distributed outcomes we reported medians and interquartile ranges. Normality was assessed using the Shapiro-Wilk test. We performed McNemar test to compare rates of hypoglycemia and hyperglycemia. We report nominal $\mathrm{p}$ values for all outcomes, and we did not do adjustment for multiple comparisons (5).

In the case of a hyperglycemic event, correction boluses were not included in the insulin outcomes since glucose levels were fixed once the correction bolus was delivered.

\section{Meal detection}

We used a model-based meal detection algorithm. The algorithm uses several mathematical models to predict glucose levels, one model with no meal and other models with hypothetical meals of different sizes. If one of the models with meals predicts sensor glucose levels significantly better than the model with no meal, then the algorithm will announce a meal with the respective size in the model.

The median meal detection time was 40.0 [40-57.5] minutes after consumption of the meal. Twenty minutes prior to meal detection, incremental glucose from mealtime was $-0.15[-0.5-0.1]$ $\mathrm{mmol} / \mathrm{L}$ with a rate of change of $6.0 \mathrm{mmol} / \mathrm{L} / \mathrm{h}[5.0-6.5]$. At 10 minutes prior to meal detection, the incremental glucose was only $1.5 \mathrm{mmol} / \mathrm{L}$ [0.9-1.8], with a rate of change of 7.9 [6.6-11.1] $\mathrm{mmol} / \mathrm{L} / \mathrm{h}$. When the meal was detected, the incremental glucose from the start of the meal was $2.6 \mathrm{mmol} / \mathrm{L}[2.4-4.8]$, with a rate of change of $10.1[7.3-12.5] \mathrm{mmol} / \mathrm{L} / \mathrm{h}$. 
A Meal Detection Algorithm for the Artificial Pancreas: A Randomized Controlled Clinical Trial in Adolescents with Type 1 Diabetes

Table S1: Comparisons of conventional pump therapy (CSII), artificial pancreas (AP), and artificial pancreas with the meal detection algorithm (AP+MDA).

\begin{tabular}{|c|c|c|c|c|c|c|}
\hline & \multirow{2}{*}{$\begin{array}{c}\text { CSII } \\
(\mathbf{N}=\mathbf{1 1})\end{array}$} & \multirow{2}{*}{$\begin{array}{c}\text { AP } \\
(\mathbf{N}=11)\end{array}$} & \multirow{2}{*}{$\begin{array}{c}\text { AP+MDA } \\
(\mathbf{N}=\mathbf{1 1})\end{array}$} & \multicolumn{3}{|c|}{$P$ value } \\
\hline & & & & CSII vs. AP & $\begin{array}{l}\text { CSII vs. } \\
\text { AP+MDA }\end{array}$ & AP vs. AP+MDA \\
\hline 4-hour iAUC* (h.mmol/L) & $24.1(9.5)$ & $19.6(10.4)$ & $15.4(8.0)$ & 0.33 & 0.03 & 0.21 \\
\hline \multicolumn{7}{|c|}{ Time spent at glucose levels (\%): } \\
\hline $3.9-10.0 \mathrm{mmol} / \mathrm{L}$ & $20.5(27.5)$ & $25.0(19.7)$ & $40.9(27.9)$ & 0.61 & 0.03 & 0.07 \\
\hline $3.9-7.8 \mathrm{mmol} / \mathrm{L}$ & $8.0(14.3)$ & $10.6(11.8)$ & $16.3(15.1)$ & 0.51 & 0.03 & 0.18 \\
\hline$<3.9 \mathrm{mmol} / \mathrm{L}$ & $0[0-0]$ & $0[0-0]$ & $0[0-0]$ & 0.34 & 0.34 & 0.8 \\
\hline$>7.8 \mathrm{mmol} / \mathrm{L}$ & $92.1(14.3)$ & $88.6(13.6)$ & $82.6(14.5)$ & 0.38 & 0.02 & 0.1 \\
\hline$>10.0 \mathrm{mmol} / \mathrm{L}$ & $79.6(27.5)$ & $74.2(20.6)$ & $58.0(26.6)$ & 0.52 & 0.02 & 0.047 \\
\hline$>13.9 \mathrm{mmol} / \mathrm{L}$ & $59.1(30.7)$ & $36.0(35.5)$ & $19.7(23.1)$ & 0.14 & 0.01 & 0.11 \\
\hline$>16.7 \mathrm{mmol} / \mathrm{L}$ & $37.5[4.2-55.2]$ & $0[0-9.4]$ & $0[0-0]$ & 0.25 & 0.046 & 0.22 \\
\hline Mean glucose $(\mathrm{mmol} / \mathrm{L})$ & $14.0(2.6)$ & $12.8(3.1)$ & $11.0(2.3)$ & 0.35 & 0.01 & 0.01 \\
\hline $\begin{array}{l}\text { Coefficient of variation } \\
(\mathrm{mmol} / \mathrm{L})\end{array}$ & $21.7(5.6)$ & $23.5(7.9)$ & $23.7(7.1)$ & 0.57 & 0.41 & 0.96 \\
\hline Total Basal Insulin (U) & $4.2(1.0)$ & $7.6(1.5)$ & $5.4(1.6)$ & $<0.01$ & 0.07 & $<0.01$ \\
\hline Total Insulin (U) & $4.2(1.0)$ & $7.6(1.5)$ & $8.6(1.8)$ & $<0.01$ & $<0.01$ & 0.09 \\
\hline 2-hour iAUC* (h.mmol/L) & $10.0(4.1)$ & $9.5(3.7)$ & $8.4(3.5)$ & 0.8 & 0.31 & 0.35 \\
\hline $\begin{array}{l}\text { 2-hour incremental glucose } \\
\text { increase }(\mathrm{mmol} / \mathrm{L})\end{array}$ & $7.7(3.0)$ & $7.1[5.1-8.8]$ & $5.9[3.4-6.7]$ & 0.6 & 0.08 & 0.1 \\
\hline $\begin{array}{l}\text { 4-hour incremental glucose } \\
\text { increase }(\mathrm{mmol} / \mathrm{L})\end{array}$ & $6.3(3.2)$ & $3.2(5.1)$ & $1.9(3.1)$ & 0.08 & 0.01 & 0.42 \\
\hline $\begin{array}{l}\text { Sensor glucose value at } 4 \\
\text { hours post-lunch }\end{array}$ & 14.4 [12.9-17.2] & 9.8 [7.9-15.9] & $8.5[6.9-10.5]$ & 0.12 & 0.01 & 0.20 \\
\hline $\begin{array}{l}\text { Sensor glucose value at } 5 \\
\text { hours post-lunch }\end{array}$ & $12.1[11.3-17.2]$ & $9.0[8.0-15.9]$ & $7.3[5.7-8.2]$ & 0.24 & 0.01 & 0.01 \\
\hline $\begin{array}{l}\text { Number of participants } \\
\text { experiencing a } \\
\text { hyperglycemia event }^{\dagger}\end{array}$ & $5 / 11$ & $4 / 11$ & $1 / 11$ & 1 & 0.13 & 0.25 \\
\hline
\end{tabular}


A Meal Detection Algorithm for the Artificial Pancreas: A Randomized Controlled Clinical Trial in Adolescents with Type 1 Diabetes

\begin{tabular}{|c|c|c|c|c|c|c|}
\hline & \multirow{2}{*}{$\begin{array}{c}\text { CSII } \\
(\mathbf{N}=11)\end{array}$} & \multirow{2}{*}{$\begin{array}{c}\mathrm{AP} \\
(\mathrm{N}=\mathbf{1 1})\end{array}$} & \multirow{2}{*}{$\begin{array}{c}\text { AP+MDA } \\
(\mathbf{N}=11)\end{array}$} & \multicolumn{3}{|c|}{$P$ value } \\
\hline & & & & CSII vs. AP & $\begin{array}{c}\text { CSII vs. } \\
\text { AP+MDA }\end{array}$ & AP vs. AP+MDA \\
\hline $\begin{array}{l}\text { Number of participants } \\
\text { experiencing a } \\
\text { hypoglycemia event }{ }^{\star}\end{array}$ & $0 / 11$ & $1 / 11$ & $0 / 11$ & 1 & NA & 1 \\
\hline
\end{tabular}

Outcomes are mean (SD) or median [IQR]. Paired differences are mean and $95 \%$ confidence interval. Outcomes are from the start of lunch to 240 minutes postlunch, unless otherwise specified. A p value of less than 0.05 is regarded as significant.

*iAUC: incremental area under the curve.

thyperglycemia event: hyperglycemia requiring insulin correction as per the protocol.

${ }^{\ddagger}$ hypoglycemia event: hypoglycemia requiring carbohydrate treatment. NA: Not applicable. 
A Meal Detection Algorithm for the Artificial Pancreas: A Randomized Controlled Clinical Trial in Adolescents with Type 1 Diabetes

Figure S1: Incremental sensor glucose from the start of lunch without a bolus (time $=0$ minutes) to 4-hours post-lunch (time $=240$ minutes) of all three interventions $(n=11)$. Blue line: conventional pump therapy (CSII). Red line: artificial pancreas (AP). Yellow line: artificial pancreas with meal detection algorithm (AP+MDA). Values are mean and standard error. P values compare the 4-hour incremental sensor glucose between arms.

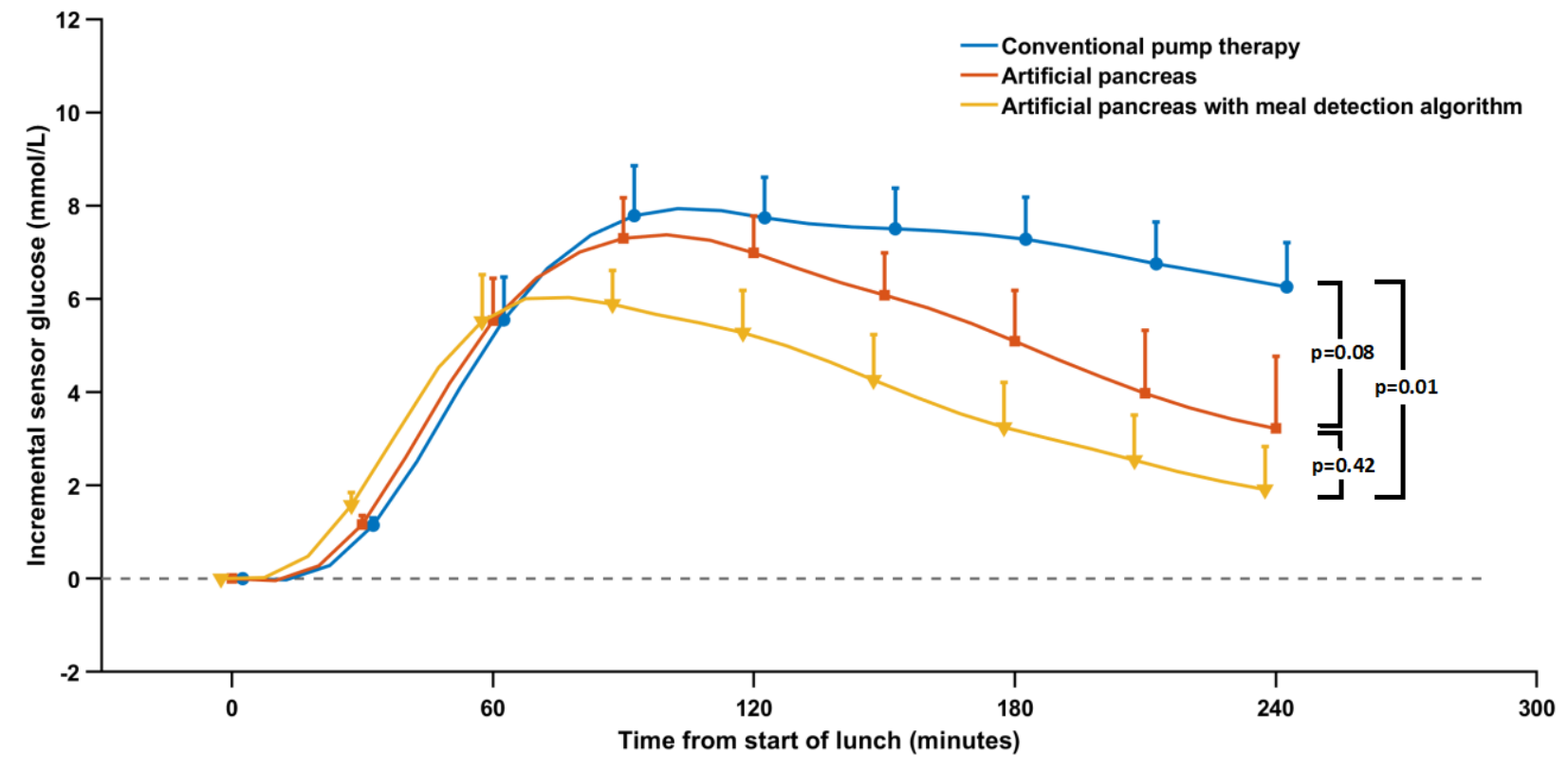

Figure S2: Incremental glucose levels 20 minutes before, 10 minutes before, and at meal detection $(n=11)$. Data indicated as a boxplot (minimum, first quartile, median, third quartile, and maximum). min: minutes.

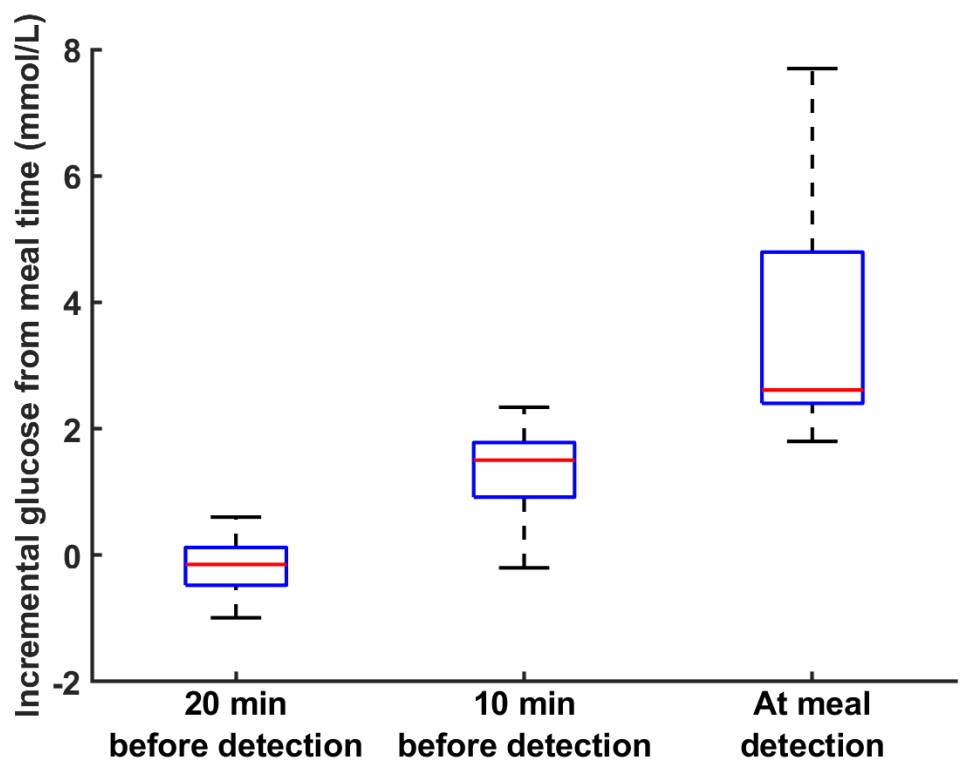

